\title{
Evaluation of the Correlation Between Childhood Asthma and Helicobacter pylori in Kashan
}

\author{
Tahere Khamechian ${ }^{1}$; Amir Hossein Movahedian ${ }^{2}$; Ghasem Ebrahimi Eskandari ${ }^{3}$; Marzieh \\ Heidarzadeh Arani $^{3, *} ;$ Abouzar Mohammadi $^{4}$ \\ ${ }^{1}$ Anatomical Sciences Research Centre, Faculty of Medicine, Kashan University of Medical Sciences, Kashan, IR Iran \\ ${ }_{2}^{2}$ Pediatric Department, Faculty of Medicine, Tehran University of Medical Sciences, Tehran, IR Iran \\ 3 Pediatric Department, Faculty of Medicine, Kashan University of Medical Sciences, Kashan, IR Iran \\ ${ }^{4}$ Surgical Technology Department, Faculty of Nursing and Midwifery, Kashan University of Medical Sciences, Kashan, IR Iran \\ ${ }^{*}$ Corresponding author: Marzieh Heidarzadeh Arani, Pediatric Department, Faculty of Medicine, Kashan University of Medical Sciences, Kashan, IR Iran. Tel: +98-9122146635, Fax: \\ +98-3615558900, E-mail: marz_heidar@yahoo.com
}

Received: January 29, 2014; Revised: June 14, 2014; Accepted: June 26, 2014

\begin{abstract}
Background: Asthma is a chronic inflammatory air-way disease with increasing prevalence rate during the recent years. There are studies about the relationship between asthma and infectious diseases, including the association between asthma and Helicobacter pylori. According to the latest studies, there is an epidemiological correlation between asthma prevalence and prevalence of H.pylori.

Objectives: The aim of this research was to study the correlation between H. pylori and asthma by biopsy in five to eighteen year-old children who had undergone endoscopy at Shahid Beheshti Hospital.

Patients and Methods: Three hundred children (5 to 18 years old) undergoing endoscopy owing to gastro-intestinal problems at Shahid Beheshti Hospital were observed for childhood asthma using the Gina 2010 questionnaire which included 24 questions with "yes" and "no" answers to identify asthmatic patients with five positive answers. Next, the patients were referred to an allergy and asthma specialist for clinical examinations, spirometry and post bronchodilator test(Post BD).

Results: Among $138 \mathrm{H}$. pylori positive patients, eight cases (5.8\%) were asthmatic while of the $162 \mathrm{H}$. pylori negative patients 28 (17.3\%) were asthmatic. This difference was statistically significant ( $\mathrm{P}$ Value $=0.002$ ). The correlation between $\mathrm{H}$. pylori and asthma was studied after controlling the confounding variables including, gender, age and family history. The results obtained for the above-mentioned variables were significant (P Values of 0.004, 0.005 and 0.002, and Odd-Ratio Mantel Haenszel (ORMH) of 3.38, 3.24 and 4.06, respectively).

Conclusions: Our findings showed that there is an inverse correlation between $H$. pylori and asthma. Performing more studies with larger sample sizes is necessary to confirm these results.
\end{abstract}

Keywords: Helicobacter pylori; Asthma; Childhood Asthma

\section{Background}

Asthma is a chronic inflammatory disease which appears with edema and inflammation. It is mostly considered as a reversible stricture in airway tracts, which could be followed by some viral respiratory infections such as respiratory syncytial virus (RSV) in children. It may present symptoms such as wheezing, shortness of breath and coughing. Although, the exact cause of asthma has not been identified, yet a combination of environmental factors, biological genetic tendencies, inhaled allergens, viral infections, and chemical-biological pollutants such as tobacco play an important role in this respect. The immunological response could be a stimulant for chronic inflammation and inappropriate healing in damaged tissue of airway tracts. These pathological processes in growing-up lungs at an early age cause negative effects upon airway tracts' growth and evolution (1).

In the United States of America, childhood asthma is one of the most common reasons of reference to the emergency departments and hospitalization. Asthma was responsible for 12.8 million absent days of school in 2004, 750000 episodes of referring to urgency services, 198000 episodes of hospitalization and 186 episodes of death in children. It has been pointed out that a combination of biological, environmental, economical, and mental risk factors could increase the possibility of severe ablaze of asthma (2). During the last decades, it seems that prevalence of childhood asthma is increasing in spite of remarkable improvement in management and pharmacotherapy (3). Several published studies in different countries have reported a 50\% increase in prevalence during the recent decade (4-7). It has been demonstrated that there is a correlation between asthma prevalence and allergic rhino conjunctivitis and atopic eczema (8).

It is assumed that childhood asthma is more common in modern capitals and crowded nations and correlates extremely with other allergic reactions (9). In compari-

Copyright (C) 2015, Ahvaz Jundishapur University of Medical Sciences. This is an open-access article distributed under the terms of the Creative Commons Attribution-NonCommercial 4.0 International License (http://creativecommons.org/licenses/by-nc/4.0/) which permits copy and redistribute the material just in noncommercial usages, provided the original work is properly cited. 
son, there is less possibility for children who live in rural areas of developing countries to become asthmatic (10). In the recent years, many studies have been conducted to determine the correlation between allergic reactions and infectious diseases (11-14). Helicobacter pylori is a urease-positive Gram-negative microaerophilic bacteria that grows in the stomach's mucosa and stimulates the human immune system (15), which helps release bacteria and host's inflammatory mediators in the blood (16). Recent studies showed that $H$. pylori could cause chronic gastritis (3), peptic ulcer disease (PUD) (6) and stomach cancer (15). In addition, there is a direct correlation between $H$. pylori infection and B-Cell lymphoma (17), and cardiac, dermal, hepatic and rheumatologic diseases (18). It has been identified that $H$. pylori could produce preinflammatory mediators such as cytokines, eicosanoids and acute phase proteins in stomach mucosa, which can explain the correlation between $H$. pylori and inflammatory diseases (19) beside the similarity of antigens of the bacterium and the host (20).

\section{Objectives}

As the correlation between H. pylori and some inflammatory diseases has been proved in the recent years, this study was conducted to study the correlation between $H$. pylori infection and childhood asthma.

\section{Patients and Methods}

Three hundred children ( 5 to 18 years old) undergoing endoscopy owing to gastro-intestinal problems at Shahid Beheshti Hospital were observed for childhood asthma by the Gina 2010 questionnaire, which includes 24 questions with "yes" and "no" answers. The children were identified as asthmatic with five positive answers (21). Next, the patients were referred to an allergy and asthma specialist for clinical examinations, spirometry, and also post bronchodilator test (Post BD). Finally, results of the questionnaires, clinical examinations, spirometric findings, and pathological reports were analyzed by the SPSS version 16.0 software, via Fisher and chi square tests.

\section{Results}

The youngest examined child was five years old while the oldest was 18 years old. One hundred and forty-three children (47.7\%) were male and 157 (52.3\%) were female. The mean age was $11.17 \pm 4.03$. Children with $H$. pylori had a mean age of $11.73 \pm 4.3$ while those without this infection had a mean age of $10.95 \pm 3.78$; no significant difference was observed $(P=0.312)$. The mean age of children with asthma was $11.23 \pm 4.07$ while the mean age of those without asthma was $10.72 \pm 3.7$, no significant difference was indicated $(\mathrm{P}=0.481)$. The Mann Whitney $\mathrm{U}$ test was used to compare the mean age of children. Forty-three of the cases (14.3\%) had an asthmatic family history. Amongst the $138 \mathrm{H}$. pylori positive patients, eight cases (5.8\%) were asthmatic while of the $162 \mathrm{H}$. pylori negative patients 28 cases (17.3\%) were asthmatic, with the difference being statistically significant $(P$ Value $=0.002)$ (Table 1$)$. The spirometric findings considered as mild, moderate and severe stages in obstruction of lower-respiratory tracts were consistent with the questionnaire; all cases of disease were confirmed by an Asthma and Allergy specialist. The correlation between $H$. pylori and asthma was studied after controlling for confounding variables, including gender, age, and family history. The obtained results for the above-mentioned variables were significant ( $P$ values of 0.004, 0.005 and 0.002, respectively) (Tables 2, 3 and 4). Also, the Odd-Ratio Mantel Haenszel (ORMH) of all of the three comparisons were obtained (ORMH gender $=3.38, \mathrm{ORMH}_{\text {age }}=3.24$ and $\mathrm{ORMH}_{\text {familial history }}=4.06$ ).

\begin{tabular}{lccc}
\hline Table 1. Frequency of Distribution of Asthma in the Two Groups of H.pylori Positive and Negative Children a,b \\
\hline Asthma & H.pylori (Positive) & H.pylori (Negative) & H.pylori (Total) \\
\hline Positive & $8(5.8)$ & $28(17.3)$ & $134(82.7)$ \\
Negative & $130(94.2)$ & $162(100)$ & $364(88)$ \\
Total & $138(100)$ & $300(100)$ \\
\hline
\end{tabular}

${ }^{\mathrm{a}}$ P Value $=0.002 ;$ OR $1=3.39 ; \mathrm{CI} 2=1.49$ - 7.7.

b Data are presented as No. (\%).

\begin{tabular}{|c|c|c|c|}
\hline Asthma & H. pylori (Positive) & H.pylori (Negative) & H.pylori (Total) \\
\hline \multicolumn{4}{|l|}{ Male } \\
\hline Positive & $3(4.5)$ & $13(17.1)$ & $16(11.2)$ \\
\hline Negative & $64(95.5)$ & $63(82.9)$ & $127(88.8)$ \\
\hline Total & $67(100)$ & $76(100)$ & $143(100)$ \\
\hline \multicolumn{4}{|l|}{ Female } \\
\hline Positive & $5(7)$ & $15(17.4)$ & $20(12.7)$ \\
\hline Negative & $66(93)$ & $71(82.6)$ & $137(87.3)$ \\
\hline Total & $71(100)$ & $86(100)$ & $157(100)$ \\
\hline
\end{tabular}

a $\mathrm{P}$ Value $=0.004$ (Mental-Haenszel); $\mathrm{OR}=3.38 ; \mathrm{CI}=1.2$ - 7.6.

b Data are presented as No. (\%). 
Khamechian T et al.

\begin{tabular}{|c|c|c|c|}
\hline Asthma & H. pylori (Positive) & H. pylori (Negative) & H. pylori (Total) \\
\hline \multicolumn{4}{|l|}{$\leq 12, y$} \\
\hline Positive & $4(3.5)$ & $21(16.7)$ & $25(10.4)$ \\
\hline Negative & $110(96.5)$ & $105(83.3)$ & $215(89.6)$ \\
\hline Total & $114(100)$ & $126(100)$ & $240(100)$ \\
\hline \multicolumn{4}{|l|}{$>12, y$} \\
\hline Positive & $4(83.3)$ & $7(19.4)$ & $11(18.3)$ \\
\hline Negative & $20(83.3)$ & $29(80.6)$ & $49(81.7)$ \\
\hline Total & $24(100)$ & $36(100)$ & $60(100)$ \\
\hline
\end{tabular}

${ }^{\mathrm{a}} \mathrm{P}$ Value $=0.005$ (Mental-Haenszel) $\mathrm{OR}=3.24 ; \mathrm{CI}=1.4-7.37$.

b Data are presented as No. (\%).

\begin{tabular}{|c|c|c|c|}
\hline Asthma (Family History Regarding of Asthma) & H. pylori (Positive) & H. pylori (Negative) & H.pylori (Total) \\
\hline \multicolumn{4}{|l|}{ Positive } \\
\hline Positive & $4(16.7)$ & $7(36.8)$ & $11(25.6)$ \\
\hline Negative & $20(83.3)$ & $12(63.2)$ & $32(74.4)$ \\
\hline Total & $24(100)$ & $19(100)$ & $43(100)$ \\
\hline \multicolumn{4}{|l|}{ Negative } \\
\hline Positive & $4(3.5)$ & $21(14.7)$ & $25(9.7)$ \\
\hline Negative & $110(96.5)$ & $122(85.3)$ & $232(90.3)$ \\
\hline Total & $114(100)$ & $143(100)$ & $257(100)$ \\
\hline
\end{tabular}

a $\mathrm{P}$ Value $=0.002$ (Mental-Haenszel); $\mathrm{OR}=4.06 ; \mathrm{CI}=1.7$ - 9.6.

b Data are presented as No. (\%).

\section{Discussion}

Among the 300 children under study, 36 (12\%) were asthmatic and 138 (46\%) were infected by $H$. pylori. The prevalence of the asthma has increased across the world for all ages, both genders, and all races from 7.3 to $8.2 \%$ during years 2001 to $2009(8,4)$. Also, in 2011, 14\% of children under 17 years of age had been described as asthmatic (22). Nowadays, attention is being paid to exogenous contacts with environmental microorganisms and their anti-genes, which are able to make harmful changes in the human immune system (11). Hygiene hypothesis is a hypothesis, which states that a lack of early childhood exposure to infectious agents, symbiotic microorganisms (e.g. gut flora or probiotics), and parasites increases susceptibility to allergic diseases by suppressing the natural development of the immune system causing change in the $\mathrm{TH} 1 / \mathrm{TH} 2$ ratio, which leads to an increase in allergic disorders (21).

It is believed that asthma could appear due to uncontrolled immunological response to environmental antigenes by $\mathrm{TH} 2$ cells. Overcoming the number of $\mathrm{TH} 2$ to $\mathrm{TH} 1$ cells resulting from less contact with environmental microorganisms causes development of asthma. According to D'Elios and Bernard, lack of TH1 cells stimulation causes hyper-activity in $\mathrm{TH} 2$ cells, which could lead to asthma (7). The $H$. pylori is a urease-positive gram-negative microaerophilic bacteria in the stomach that has spread in most populations. The $H$. pylori remains in the mucosal layer of the stomach for decades and people under the age of ten could become infected and transfer the infection to other family members as well (14). The antibody response following $H$. pylori infection would remain stably with $H$. pyloric gastric colonization for decades or for an entire lifetime. It has been determined that colonization of $H$. pylori in the mucosal layer of the stomach would increase different pre-inflammatory mediators such as cytokines and acute phase proteins (23). Therefore, there is a pathogenic correlation between $H$. pylori infection and the diseases, which would appear by action of inflammatory mediators and/or auto-immune induction (12). Helicobacter pylori infection decreases TH2 cells leading to a reduction of TH1 cells number (24). It can also decrease the prevalence of severe allergic responses by induction of regulatory T cells $(2,25)$.

In the current study, 138 cases (46\%) out of 300 were H. pylori positive as illustrated by their biopsy samples. Several 
studies have been performed on the correlation of oral-fecal infections and asthma with controversial results. Helicobacter pylori has been introduced as an allergy stimulant by some researches (26), while others claim that it has a protective role against allergies (27) and a number of studies suggest its miscorrelation with allergic diseases (13). Among the $138 \mathrm{H}$. pylori positive patients, eight cases (5.8\%) and among the $162 \mathrm{H}$. pylori negative, 28 cases $(17.3 \%$ ) were asthmatic, showing a statistic difference with odds ratio of 3.39. The obtained results are compatible with several other studies in which an inverse correlation between $\mathrm{H}$. pylori anti-bodies and asthma has been revealed. For instance, results obtained by Arram et al. pointed out that there is a significant difference in $\mathrm{H}$. pylori infection in asthmatic patients compared with the control group (9). The study of Chen and Blaser indicated that H. pylori infection could significantly reduce the risk of asthma and emphasized that performing more researches in order to orientate the exact mechanisms of action are necessary (5).

Study of Zevit et al. on 6959 children indicated that there is an inverse correlation between childhood asthma and H. pylori infection (28). However, Tsang et al. (29) and Jaber (30) showed that there is no correlation between $H$. pylori infection and asthma. There is little evidence on the inverse correlation between $H$. pylori and asthma as indicated by Wang et al. (31). Fullerton et al. in a study performed on 2437 patients showed that there is no correlation between $H$. pylori serology and pulmonary function tests (10). The diagnostic method of $H$. pylori has been different in previous studies. Some used $H$. pylori serology tests in which sensitivity and specificity related to variables play an important role (50 to $100 \%$ ); and this could be a strong confounding factor and also a justification for the obtained incommensurable results in the above-mentioned researches. On the other hand, some factors such as gender, age, and family history of asthma could be considered as strong confounding factors, which affect $H$. pylori and asthma leading to incommensurable results.

The advantage of the present study is that some features such as age, gender, and family history were considered in the assessment of patients and that diagnosis of H. pylori infection was made by the biopsy method, which has a higher sensitivity and specificity than serology tests. There is an inverse correlation between H. pylori and asthma as indicated by our findings. Performing more studies with larger sample sizes is necessary to confirm these results. Obviously, precise recognition of the correlation between $H$. pylori infection and asthma could play an important role in the recognition of the physiopathology of not only asthma but also other allergic diseases, which would offer potentially helpful new treatments for allergic diseases.

\section{References}

1. Liu AH, Spahn JD, Leung DYM. Childhood Asthma. In: Kliegman RM, Stanton B, Geme JS, Schor N, Behrman RE editors. Nelson Textbook of Pediatrics. 19 ed: Saunders Elsevier; 2012.
2. Arnold IC, Dehzad N, Reuter S, Martin H, Becher B, Taube C, et al Helicobacter pylori infection prevents allergic asthma in mouse models through the induction of regulatory T cells. J Clin Investigation. 2011;121(8):3088-93.

3. Cave DR, editor. Chronic gastritis and Helicobacter pylori; Seminars in gastrointestinal disease.; 2001; pp. 196-202.

4. Centers for Disease Control Prevention.. Vital signs: asthma prevalence, disease characteristics, and self-management education: United States, 2001-2009. Morbidity Mortality Weekly Rep. 2011;60(17):547.

5. Chen Y, Blaser MJ. Helicobacter pylori colonization is inversely associated with childhood asthma. Infect Dis. 2008; 198(4):553-60.

6. Cohen H. Peptic Ulcer and Helicobacter Pylori. Gastroenterol Clin North America. 2000;29(4):775-89.

7. D'Elios MM, Bernard MD. To treat or not to treatHelicobacte pylorito benefit asthma patients. Expert Rev Respir Med. 2010;4(2):147-50.

8. Eder W, Ege MJ, Von Mutius E. The asthma epidemic. N Engl J Med 2006;355(21):2226-35.

9. Arram EO, Shahin DA, Sherif MM. Asthma is inversely associated with Helicobacter pylori status. Egyptian J Chest Dis Tuberc 2012;61(3):41-5.

10. Fullerton D, Britton JR, Lewis SA, Pavord ID, McKeever TM, Fog arty AW. Helicobacter pylori and lung function, asthma, atopy and allergic disease--a population-based cross-sectional study in adults. Int J Epidemiol. 2009;38(2):419-26.

11. Gold DR, Wright R. Population disparities in asthma. Annu Rev Public Health. 2005;26:89-113.

12. Jun ZJ, Lei Y, Shimizu Y, Dobashi K, Mori M. Helicobacter pylori Seroprevalence in Patients with Mild Asthma. The Tohoku J Exp Med. 2005;207(4):287-91.

13. Kolho K, Haapaniemi A, Haahtela T, Rautelin H. Helicobacter pylori and Specific Immunoglobulin E Antibodies to Food Allergens in Children. J Pediatr Gastroenterol Nutr. 2005;40(2):180-3.

14. Kosunen TU, Aromaa A, Knekt P, Salomaa A, Rautelin H, Lohi P, et al. Helicobacter antibodies in 1973 and 1994 in the adult population of Vammala, Finland. Epidemiol Infect. 1997;119(1):29-34.

15. Xue FB, Xu YY, Wan Y, Pan BR, Ren J, Fan DM. Association of H. pylori infection with gastric carcinoma: a Meta analysis. World $J$ Gastroenterol. 2001;7(6):801-4

16. Peterson WL. Helicobacter pylori. Gastroenterol. 1998;114(1):224

17. Parsonnet J, Hansen S, Rodriguez L, Gelb AB, Warnke RA, Jellum E et al. Helicobacter pylori infection and gastric lymphoma. NEng J Med.1994;330(18):1267-71.

18. Realdi G, Dore MP, Fastame L. Extradigestive manifestations of Helicobacter pylori infection: fact and fiction. Dig Dis Sci. 1999; 44(2):229-36.

19. Kountouras J, Boura P, Lygidakis NJ. Omeprazole and regulation of cytokine profile in Helicobacter pylori-infected patients with duodenal ulcer disease. Hepatogastroenterology. 2000 47(35):1301-4.

20. Negrini R, Savio A, Poiesi C, Appelmelk BJ, Buffoli F, Paterlini A, et al. Antigenic mimicry between Helicobacter pylori and gastric mucosa in the pathogenesis of body atrophic gastritis. Gastroenterology. 1996;111(3):655-65

21. Strachan DP. Family size, infection and atopy: the first decade of the "hygiene hypothesis". Thorax. 2000;55 Suppl 1:S2-10

22. Bloom B, Cohen RA, Freeman G. Summary health statistics for US children: National Health Interview Survey, 2009. Vital Health Statistics. 2010;2010(247):1-82.

23. Takahashi S, Nakamura E, Okabe S. Effects of cytokines, without and with Helicobacter pylori components, on mucus secretion by cultured gastric epithelial cells. Dig Dis Sci.1998;43(10):2301-8

24. Wang Y, Bi Y, Zhang L, Wang C. Is Helicobacter pylori infection associated with asthma risk? A meta-analysis based on 770 cases and 785 controls. Int J Med Sci. 2012;9(7):603.

25. Strickland DH, Judd S, Thomas JA, Larcombe AN, Sly PD, Holt PG. Boosting airway T-regulatory cells by gastrointestinal stimulation as a strategy for asthma control. Mucosal Immuno .2010;4(1):43-52.

26. Liutu M, Kalimo K, Kalimo H, Uksila J, Leino R. Mast cells and IgEcontaining cells in gastric mucosa of Helicobacter pylori infect- 


\section{Khamechian T et al.}

ed and non-infected patients with chronic urticaria. J European Acad Dermatol Venereol. 2004;18(1):69-72.

27. McCune A, Lane A, Murray L, Harvey I, Nair P, Donovan J, et al. Reduced risk of atopic disorders in adults with Helicobacter pylori infection. European J Gastroenterol Hepatol. 2003;15(6):637-40.

28. Zevit N, Balicer RD, Cohen HA, Karsh D, Niv Y, Shamir R. Inverse Association Between Helicobacter pylori and Pediatric Asthma in a High - Prevalence Population. Helicobacter. 2012;17(1):30-5.
29. Tsang KW, Lam WK, Chan KN, Hu W, Wu A, Kwok E, et al. Helicobacter pylori sero-prevalence in asthma. Respir Med. 2000;94(8):756-9.

30. Jaber SM. Helicobacter pylori seropositivity in children with chronic disease in Jeddah, Saudi Arabia. Saudi J Gastroenterol. 2006;12(1):21.

31. Wang Q, Yu C, Sun Y. The Association Between Asthma and Helicobacter pylori: A Meta - Analysis. Helicobacter. 2013;18(1):41-53. 